\title{
진행파동장하 해저지반내 잔류간극수압의 해석해 An Analytical Solution of Progressive Wave-Induced Residual Pore-Water Pressure in Seabed
}

\author{
이광호* ·김동욱** · 김도삼*** · 김태형*** · 김규한**** · 류흥원** \\ Kwang-Ho Lee*, Dong-Wook Kim**, Do-Sam Kim***, Tae-Hyung Kim***, \\ Kyu-Han Kim**** and Heung Won Ryu**
}

\begin{abstract}
요 지 : 본 연구에서는 잔류간극수압의 추정에 관한 기존의 해석해에서 지적된 오류를 수정한 새로운 해석해를 제 시한다. Fourier급수전개법과 변수분리법으로 산정된 해석해의 타당성은 기존의 해석해, 수치해석해 및 실험결과와 비교·검토로부터 검증된다. 무한 (깊은)두께의 본 해석해는 기존의 해석해보다는 수치적분 등이 수행될 필요가 없 는 보다 간단한 식이다. 유한두께에 관한 해석해에 지반두께를 매우 작게 한 경우 극한의 얕은 두께로 점근적인 접 근은 가능하지만, 지반두께를 매우 크게 한 경우 극한의 무한두께로 접근은 불가능하며, 유한두께와 무한두께의 사 이에는 불연속적인 영역이 존재한다.
\end{abstract}

핵심용어 : 해저지반, 진행파, 잔류간극수압, 해석해, 무한두께

\begin{abstract}
In this paper, the errors found in the existed analytical solutions described the mechanism of residual pore-water pressure accumulation were examined and a new analytical was proposed. The new analytical solution was derived by using a Fourier series expansion and separation of variables was verified by comparison with the existed both analytical and numerical solutions and experimental result. The new analytical solution is very simple that there is no need for numerical integration for deep soil thickness. In addition, the solutions of the residual porewater pressure for finite, deep, and shallow soil thickness reveled that it is possible to approach from finite to shallow soil thickness, but not possible to deep soil thickness because there was discontinues zone between finite and deep soil thickness.
\end{abstract}

Keywords : seabed, progressive waves, residual pore-water pressure, analytical solution, deep soil thickness

\section{1. 서 론}

파동으로 인한 해저지반거동의 평가는 offshore mono-pile, 방파제, 파이프라인과 플랫폼 등의 많은 해양-해안구조물의 설계에서 매우 중요한 항목이며, 파동으로 인한 간극수압의 예측은 액상화나 세굴과 같은 지반불안정해석에서 주된 요소 이다. 여기서, 간극수압은 진동간극수압과 잔류간극수압으로 분류되고, 이들은 현장관측과 실험으로부터 각각 다른 메커 니즘으로 발생하는 것으로 알려져 있다 (Zen and Yamazaki, 1991). 전자는 과도 혹은 진동간극수압으로부터 발생되고, 간 극수압의 변동에서 진폭감쇠 및 위상지연이 수반된다 (Yamamoto et al., 1978; Jeng, 1997). 후자는 반복하중하의 흙 체적감소에 의한 간극수압의 축적으로부터 발생되는 것으
로 알려져 있다 (Seed and Rahman, 1978). 주기적인 단순반 복하중을 받는 포화비점성토질에서는 잔류간극수압이 나타나 지 않지만, 느슨한 포화실트나 가는 모래에서 간극수압은 반 복하중의 횟수에 따라 증가하며 (Seed and Lee, 1966; Seed et al., 1978), 이 때 반복하중에 의한 간극수압의 축적이 배수 에 의한 소산을 초과하는 경우 간극수압의 純축적으로 이어진 다. 따라서, 상재하중의 대부분을 간극수가 지지하고, 경우에 따라 유효응력이 크게 감소되는 수준까지 간극수압이 증가할 수 있고, 따라서 액상화에 의한 지반파괴가 발생될 수 있다.

일반적으로 지진하중에 의한 액상화는 오래 전부터 많은 사 례연구와 현장관측 등을 통하여 발생메커니즘과 해석법 등이 잘 정립되어 왔다 (예로, Seed and Idriss, 1971, 1982; Castro, 1975; Ishihara, 1993; Ishihara et al., 1993; Hamada et al.,

*가톨릭관동대학교 에너지자원플랜트공학과(Dept. of Energy Resources and Plant Eng., Catholic Kwandong Univ., Gangwon)

**한국해양대학교 토목환경공학과(Dept. of Civil and Environmental Eng., Korea Maritime and Ocean Univ., 727 Taejong-ro, Yeongdo-ku, Busan)

***한국해양대학교 건설공학과(Corresponding author: Do-Sam Kim, Dept. of Civil Eng., Korea Maritime and Ocean Univ., 727 Taejong-ro, Yeongdo-ku, Busan 606-791, Korea, Tel:+82-51-410-4463, Fax:+82-51-403-0656, kimds@kmou.ac.kr)

****가톨릭관동대학교 토목공학과(Dept. of Energy Resources and Plant Eng., Catholic Kwandong Univ., Gangwon) 
1994). 반면에, 파동환경하 간극수압의 축적이 현지시험으로 부터 관측은 되었지만, 그의 해석법은 de Alba et al. (1976) 과 Seed and Rahman (1978)의 의한 반복하중과 간극수압의 축적과의 관계가 제안된 이후인 것으로 판단된다. 잔류간극 수압에 관한 실험연구로 진행파에 대한 Clukey et al. (1985), Sassa et al. (2001), 완전중복파에 대한 Kirca et al. (2013) 및 원심모형기에 의한 Sassa and Sekiguchi (1999)의 연구 등 을 들 수 있고, 수치연구로 random-walk모형에 기초한 Sumer and Cheng (1999), two-layer모델에 기초한 Sassa et al. (2001), 유한요소법에 기초한 Sassa and Sekiguchi (2001), Biot형의 기초방정식에 기초한 Sawicki and Mierczynki (2005)의 연구 등을 들 수 있으며, 해석해의 유도에 대해서는 Fourier급수전개법에 기초한 McDougal et al. (1989), Cheng et al. (2001), Jeng (2008), Laplace변환법에 기초한 Jeng et al. (2006), Jeng and Seymour (2007) 등의 연구를 들 수 있다. 여기서, 주된 해석해는 McDougal et al. (1989), Cheng et al. (2001) 및 Jeng et al. (2006)에 의해 각각 유도되었으며, 모두 $\operatorname{Biot}$ (1941)의 저류방정식에 기초한 1차원압밀방정식을 기초방 정식으로 적용하고 있다. 여기서, Jeng et al. (2006)은 McDougal et al. (1989)과 Cheng et al. (2001)의 정식화 과정 에 오류가 있는 것으로 지적하고, 새로운 Laplace변환법에 기 초한 해석법을 제안하고 있다.

본 연구에서는 McDougal et al. (1989)과 Cheng et al. (2001)에서 지적된 오류를 수정하고, Jeng et al. (2006)의 해석 해와는 다른 형태의 해석해를 제시함과 동시에 Cheng et al. (2001)과 Jeng et al. (2007)의 연구결과 및 Clukey et al. (1983)의 실험결과와 비교하여 해의 타당성을 검증하고, 또한 유한, 무한 및 얕은 두께의 해저지반에 대한 잔류간극수압의 해의 특성을 논의한다.

\section{2. 해석이론}

\section{1 정식화}

2.1.1 지배방정식과 경계조건

본 연구에서는 해저지반내 잔류간극수압의 동적응답을 모 델화하기 위하여 McDougal et al. (1989), Cheng et al. (2001) 및 Jeng et al. (2006)과 같이 Biot압밀방정식 (Biot, 1941)을 사용한다. Fig. 1의 선형규칙진행파동장하 해저지반 에 대해 정의되는 좌표계에서 균질등방토질에 관한 Biot압밀 방정식은 다음과 같이 주어진다 (Biot, 1941).

$$
\frac{\partial^{2} P}{\partial x^{2}}+\frac{\partial^{2} P}{\partial z^{2}}-\frac{\rho g n^{\prime} \zeta}{K} \frac{\partial P}{\partial t}=\frac{\rho g}{K} \frac{\partial}{\partial t}\left(\frac{\partial \xi}{\partial x}+\frac{\partial \chi}{\partial z}\right)
$$

여기서, $x$ 와 $z$ 는 수평과 연직좌표, $P$ 는 정수압을 기준으로 파 동으로 인한 간극수압, $K$ 는 흙의 투수계수, $\rho$ 는 간극수의 밀 도, $g$ 는 중력가속도, $n^{\prime}$ 는 흙의 간극률, $t$ 는 시간, $\zeta$ 는 간극 수의 압축률로 포화도와 겉보기체적탄성계수와 관련되며, $\xi$ 와

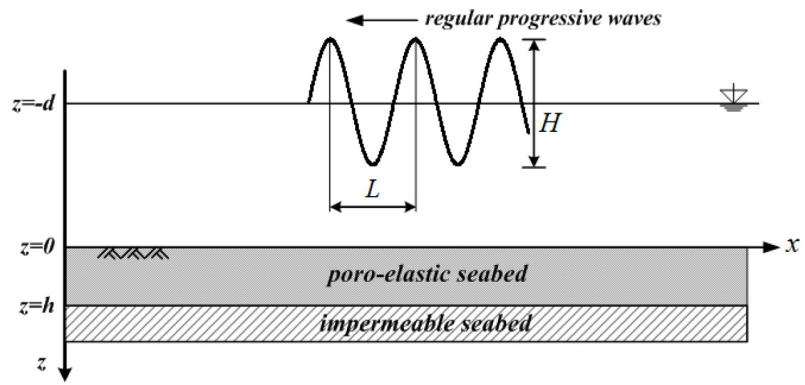

Fig. 1. Definition of wave-seabed interaction system.

$\chi$ 는 각각 $x$ 와 $z$ 방향의 지반변위이다.

유효응력개념과 Hooke법칙으로부터 다음의 평형방정식이 얻어진다.

$$
\begin{aligned}
& G \nabla^{2} \xi+\frac{G}{1-2 \mu} \frac{\partial}{\partial x}\left(\frac{\partial \xi}{\partial x}+\frac{\partial \chi}{\partial z}\right)=\frac{\partial P}{\partial x} \\
& G \nabla^{2} \chi+\frac{G}{1-2 \mu} \frac{\partial}{\partial z}\left(\frac{\partial \xi}{\partial x}+\frac{\partial \chi}{\partial z}\right)=\frac{\partial P}{\partial z}
\end{aligned}
$$

여기서, $G$ 는 흙의 전단탄성계수, $\mu$ 는 훍의 Poisson비이다.

해저지반내 연직깊이의 함수인 간극수압의 응답에서 연 직방향으로는 위상차가 발생되지 않는 것으로 알려 있다 ( 예로, Yamamoto et al., 1978). 따라서, 일정수심상에서 선 형규칙진행파만이 존재하는 경우 진동간극수압을 한 주기 에 걸쳐 평균하면 0 으로 주어지고, 간극수압에서 잔류성분 만이 존재하게 된다. 해저지반내 잔류간극수압은 수평위치 와 관련된 시간의 위상차를 제외하면 동일한 연직깊이인 다 른 수평위치에서 동일하므로 해저지반내 잔류간극수압의 변 동은 일정수심상의 선형규칙진행파에 한정하면 1 차원문제 로 고려될 수 있고, 따라서 식 (1) (3)은 다음과 같이 주어 진다.

$$
\begin{aligned}
& \frac{\rho g n^{\prime} \zeta}{K} \frac{\partial P}{\partial t}+\frac{\rho g}{K} \frac{\partial^{2} \chi}{\partial t \partial z}=\frac{\partial^{2} P}{\partial z^{2}} \\
& 2 G\left(\frac{1-\mu}{1-2 \mu}\right) \frac{\partial^{2} \chi}{\partial z^{2}}=\frac{\partial P}{\partial z}
\end{aligned}
$$

식 (4)와 (5)으로부터 $\chi$ 를 소거한 결과식을 $z$ 에 관하여 적 분하면 다음의 식이 도출된다.

$$
\frac{\partial P}{\partial t}=c_{v} \frac{\partial^{2} P}{\partial z^{2}}+s
$$

식 (6)이 통상 지진압밀방정식으로 불리며, $s$ 는 적분상수로 후술하는 잔류간극수압의 원천항 (source term)과 연관되고, $c_{v}$ 는 압밀계수로 다음과 같이 주어진다.

$$
c_{v}=\frac{G K}{\rho g} \frac{2(1-\mu)}{(1-2 \mu)+2 n^{\prime} \zeta G(1-\mu)}
$$

다음으로, 식 (6)을 파의 한 주기 $\bar{T}$ 에 걸쳐 시간평균하면 잔류간극수압에 대한 다음과 같은 지배방정식이 얻어진다. 
$\frac{\partial u}{\partial t}=c_{v} \frac{\partial^{2} u}{\partial z^{2}}+f$

여기서, $u$ 는 잔류간극수압, $f$ 는 잔류간극수압의 원천항으로, 각각 다음과 같이 각각 정의된다.

$$
\begin{aligned}
& u=\frac{1}{\bar{T}} \int_{t}^{+\bar{T}} P d t \\
& f=\frac{1}{\bar{T}} \int_{t}^{+\bar{T}} s d t
\end{aligned}
$$

간극수압의 축적, 즉 잔류간극수압의 거동에 대한 해석해 를 도출하는 문제는 식 (8)의 해석해를 유도하는 것으로 귀 착되고, 따라서 다음과 같은 경계 및 초기조건을 부과할 수 있다 (McDougal et al., 1989).

$$
\begin{aligned}
& u(0, t)=0 \\
& \frac{\partial u(h, t)}{\partial z}=0 \\
& u(z, 0)=0
\end{aligned}
$$

여기서, $h$ 는 해저면상에서 해저지반하의 불투수층까지 지반 두께를 나타내며, 식 (11)과 (12)는 각각 해저면상 $z=0$ 에서 잔류간극수압이 0 이고, $z=h$ 의 불투수층을 통한 흐름이 없 다는 것을 의미하며, 식 (13)은 초기조건으로 잔류간극수압의 초기분포가 0 이라는 것을 나타낸다.

\subsection{2 잔류간극수압의 원천항}

잔류간극수압의 해석해를 유도한 McDougal et al. (1989), Cheng et al. (2001) 및 Jeng et al. (2006)은 잔류간극수압의 원천항이 지진시 간극수압의 발달과 유사하게 전개될 수 있 는 것으로 가정하고, 단순전단에서 하중반복횟수와 잔류간극 수압의 발달관계를 도출한 de Alba et al. (1976)에 의한 실험 관계식, 잔류간극수압의 발생비와 반복비 사이에 Seed et al. (1975)에 의한 관계식 및 액상화에 대한 반복횟수와 반복전단 응력비 사이에 Seed and Rahman (1978)에 의한 관계식 등을 적용하여 다음과 같은 잔류간극수압의 원천항을 제시하고 있다.

$$
f=\frac{\sigma_{0}^{\prime}}{\bar{T}}\left(\frac{\tau}{\alpha \sigma_{0}^{\prime}}\right)^{-1 / \beta}
$$

여기서, $\alpha$ 와 $\beta$ 는 흙의 종류와 상대밀도의 함수인 무차원계수, $\tau$ 는 해저지반내에서 최대전단응력으로 진동간극수압의 해석 으로부터 산정될 수 있고, $\sigma_{0}{ }^{\prime}$ 는 유효상재하중으로 다음의 식 으로 주어질 수 있다.

$$
\sigma_{0}^{\prime}=\rho_{\text {sub }} g z \frac{1+2 k_{0}}{3}
$$

여기서, $\rho_{s u b}=\rho_{s}-\rho$ 으로 훍의 수중질량중량이며, $\rho_{s}$ 는 훍
의 밀도, $k_{0}$ 는 정지토압계수이다.

\subsection{3 진행파동장하 전단응력}

Fig. 1 에 나타내는 바와 같이 수심 $d$, 파장 $L$ 혹은 주기 $\bar{T}$ 및 파고 $H$ 를 갖는 선형규칙진행파로 인하여 지반두께 $h$ 를 갖 는 해저지반내에서 발생되는 최대전단응력은 진동간극수압의 해석으로부터 다음과 같이 주어질 수 있다 (예로, Yamamoto et al., 1978).

$$
\tau(z)=A_{1} e^{k z}+A_{2} e^{-k z}+A_{3} z e^{k z}+A_{4} z e^{-k z}+A_{5} e^{k \delta z}+A_{6} e^{-k \delta z}
$$

여기서, $A_{j}(j=1 \sim 6)$ 는 진동간극수압의 해석으로부터 산정되 는 복소미정계수, $k$ 는 진행파의 파수, $\delta$ 는 다음의 식으로 정 의되는 복소계수이다.

$$
\delta=\sqrt{1+i \frac{\omega}{c_{v} k^{2}}}
$$

여기서, $\omega$ 는 진행파의 각주파수를 나타낸다.

\section{2 해석해의 유도}

유한두께를 갖는 해저지반에 대해 경계치문제는 식 (8)과 (11) (13)으로 주어진다. 잔류간극수압의 원천항은 시간과는 무관한 항이기 때문에 잔류간극수압 $u$ 를 시간과 무관한 항 $u_{1}$ 과 시간의 함수인 항 $u_{2}$ 와의 합으로 다음과 같이 나타낸다.

$$
u(z, t)=u_{1}(z)+u_{2}(z, t)
$$

식 (18)을 고려하면 경계치문제에 관한 식 (8)과 (11) (13) 은 다음과 같이 재구성된다.

$$
\begin{aligned}
& c_{v} \frac{\partial^{2} u_{1}(z)}{\partial z^{2}}=-f(z) \\
& \frac{\partial u_{1}(h)}{\partial z}=0 \\
& \frac{\partial u_{2}(z, t)}{\partial t}=c_{v} \frac{\partial^{2} u_{2}(z, t)}{\partial z^{2}} \\
& \frac{\partial u_{2}(h, t)}{\partial z}=0 \\
& u_{2}(0, t)=-u_{1}(0) \\
& u_{1}(z)+u_{2}(z, 0)=0
\end{aligned}
$$

2.2.1 유한두께의 해저지반에 대한 해석해

$u_{1}(z)$ 에 관하여 $f(z)$ 를 주기 $4 h$ 인 기함수의 변화를 고려 한 Fourier급수전개법과 열전도방정식의 형으로 주어지는 $u_{2}(z)$ 에 변수분리법을 적용하여 식 (19) (24)로부터 유한두 께의 해저토층내 잔류간극수압에 관한 해석해를 산정하면 다 음과 같이 도출될 수 있다. 


$$
u(z, t)=\sum_{n=1}^{\infty} a_{n} \sin \left(\frac{k_{n}}{h} z\right)\left[1-\exp \left\{-c_{v}\left(\frac{k_{n}}{h}\right)^{2} t\right\}\right]
$$

여기서, $a_{n}$ 과 $k_{n}$ 은 다음의 식으로 주어진다.

$$
\begin{aligned}
& a_{n}=\frac{2 h}{c_{v} k_{n} \int_{0}^{h} f(z) \sin \left(\frac{k_{n}}{h} z\right) d z} \\
& k_{n}=\frac{(2 n-1) \pi}{2}
\end{aligned}
$$

식 (25)는 Cheng et al. (2001)과 Jeng et al. (2006)에 의 한 결과와 동일하지만, McDougal et al. (1989)의 결과와는 유사하다. 무한시간에서는 다음의 식으로 나타난다.

$$
u(z, t)=\sum_{n=1}^{\infty} a_{n} \sin \left(\frac{k_{n}}{h} z\right)
$$

2.2.2 얕은 두께의 해저지반에 대한 해석해 $h / L<1 / 20$ ( $L$ 은 진행파의 파장)인 얕은 두께의 토층에서 전 단응력은 다음의 식에 나타내는 바와 같이 해저표면상에서 0 을 갖고 연직깊이의 증가와 더불어 거의 선형적으로 증가하 는 것으로 알려져 있다 (예로, Yamamoto et al., 1978).

$$
\tau=m p_{0} z
$$

여기서, $p_{0}$ 는 해저표면상에서 파로 인한 최대동압을 나타내 며, 계수 $m$ 은 식 (16)과 (29)를 등치하고, 토층의 전연직깊이 에 대해 적분하면 (McDougal et al., 1989; Jeng et al., 2006) 다음과 같이 얻어진다.

$$
\begin{gathered}
m=\frac{2}{\delta k^{2} h^{2} p_{0}}\left[A_{1} k \delta\left(e^{k h}-1\right)-A_{2} k \delta\left(e^{-k h}-1\right)+A_{3} \delta\left\{k h e^{k h}-\left(e^{k h}-1\right)\right\}\right. \\
\left.-A_{4} \delta\left\{k h e^{-k h}+\left(e^{-k h}-1\right)\right\}+A_{5} k\left(e^{k \delta h}-1\right)-A_{6} k\left(e^{-k \delta h}-1\right)\right]
\end{gathered}
$$

한편, 식 (14)에 (15)과 (29)의 결과를 대입하면 잔류간극 수압의 원천항은 다음과 같이 주어진다.

$$
f(z)=\frac{\rho_{\text {sub }} g\left(1+2 k_{0}\right)}{3 \bar{T}}\left[\frac{3 m p_{0}}{\alpha \rho_{\text {sub }} g\left(1+2 k_{0}\right)}\right]^{-1 / \beta} z
$$

식 (18) (24)에 (31)을 고려하고, Fourier급수전개법 및 변 수분리법을 적용하여 얕은 토층에 관한 잔류간극수압의 해석 해를 산정하면 다음과 같이 얻어질 수 있다.

$u(z, t)$

$$
=\frac{a}{2 c_{v}}\left[z\left(h^{2}-\frac{1}{3} z^{2}\right)+4 h^{3} \sum_{n=1}^{\infty} \frac{(-1)^{n}}{k_{n}^{4}} \sin \left(\frac{k_{n}}{h} z\right) \exp \left\{-c_{v}\left(\frac{k_{n}}{h}\right)^{2} t\right\}\right]
$$

식 (32)는 Jeng et al. (2006)의 결과와 동일하고, McDougal et al. (1989)와는 유사하지만, 본 계산에서 McDougal et al. (1989)의 결과를 수정·확장한 결과이다. 무
한시간에서는 다음의 식으로 나타난다.

$$
u(z, t)=\frac{a}{2 c_{v}} z\left(h^{2}-\frac{1}{3} z^{2}\right)
$$

2.2.3 무한 (깊은)두께의 해저지반에 대한 해석해

$h / L>1 / 2$ 인 무한 (깊은)두께의 토층에서 전단응력을 다음 과 같이 나타낼 수 있다 (예로, Yamamoto et al., 1978).

$$
\tau=p_{0} k z e^{-k z}
$$

식 (34)과 (15)를 (14)에 대입하여 다음의 관계식을 나타낼 수 있다.

$$
f(z)=\frac{1}{T}\left(\frac{p_{0} k}{\alpha}\right)^{-1 / \beta}\left[\frac{\rho_{s u b} g\left(1+2 k_{0}\right)}{3}\right]^{1+1 / \beta} z e^{k z / \beta}
$$

다음과 같은 무차원변수를 도입한다.

$$
\begin{aligned}
& Z=\frac{z}{h} \\
& T=\frac{c_{v} t}{h^{2}} \\
& U=\frac{c_{v} \bar{T}}{\rho_{\text {sub }} g h^{3}}\left(\frac{p_{0} k}{\alpha \rho_{\text {sub }} g}\right)^{1 / \beta}\left(\frac{1+2 k_{0}}{3}\right)^{-1-1 / \beta} u
\end{aligned}
$$

식 (36) (38)을 (18) (24)에 적용하면 다음과 같이 무차원 화된 지배방정식과 경계조건을 나타낼 수 있다.

$$
\begin{aligned}
& \frac{\partial^{2} U_{1}(Z)}{\partial Z^{2}}=Z e^{A Z / \beta} \\
& \frac{\partial U_{1}(Z)}{\partial Z}=0 \text { on } Z=1 \\
& \frac{\partial U_{2}(Z, T)}{\partial T}=\frac{\partial^{2} U_{2}(Z, T)}{\partial Z^{2}} \\
& \frac{\partial U_{2}(Z, T)}{\partial Z}=0 \text { on } Z=1 \\
& U(0, T)=0 \\
& U(Z, 0)=0
\end{aligned}
$$

여기서, $\Lambda=k h$ 로 무차원파수를 나타낸다.

$U_{1}(Z)$ 의 해석에 Fourier급수전개법과 $U_{2}(Z, T)$ 의 해석에 변수 분리법을 각각 적용하여 경계조건을 만족하는 $U(Z, T)$ $=U_{1}(Z)+U_{2}(Z, T)$ 의 해를 산정하면 다음과 같이 주어질 수 있다.

$$
U(Z, T)=\sum_{n=1}^{\infty} F_{n} \sin k_{n} Z\left[1-\exp \left(-k_{n}^{2} T\right)\right]
$$

여기서, 계수 $F_{n}$ 은 다음과 같이 주어진다.

$$
F_{n}=\frac{2}{k_{n}^{2}}\left[\frac{(-1)^{n+1} e^{\Theta}}{k_{n}^{2}+\Theta^{2}}\left(\frac{k_{n}^{2}-\Theta^{2}}{k_{n}^{2}+\Theta^{2}}+\Theta\right)-\frac{2 k_{n} \Theta}{\left(k_{n}^{2}+\Theta^{2}\right)^{2}}\right]
$$


여기서, $\Theta=\Lambda / \beta$ 이다.

식 (45)와 (46)은 McDougal et al.(1989)의 무차원과정에 서 지적된 오류를 수정하여 새롭게 산정된 결과이며, 차원량 으로 나타내면 다음의 식과 같다.

$$
\begin{aligned}
& u(z, t)=\frac{\rho_{\text {sub }} g h^{3}}{c_{v} \bar{T}}\left(\frac{p_{0} k}{\alpha \rho_{\text {sub }} g}\right)^{-1 / \beta}\left(\frac{1+2 k_{0}}{3}\right)^{1+1 / \beta} \\
& \cdot \sum_{n=1}^{\infty} F_{n} \sin \left(\frac{k_{n}}{h} z\right)\left[1-\exp \left\{-c_{v}\left(\frac{k_{n}}{h}\right)^{2} t\right\}\right]
\end{aligned}
$$

무한시간에서 잔류간극수압은 식 (47)로부터 다음과 같이 주어질 수 있다.

$$
u(z, t)=\frac{\rho_{\text {sub }} g h^{3}}{c_{v} \bar{T}}\left(\frac{p_{0} k}{\alpha \rho_{\text {sub }} g}\right)^{-1 / \beta}\left(\frac{1+2 k_{0}}{3}\right)^{1+1 / \beta} \sum_{n=1}^{\infty} F_{n} \sin \left(\frac{k_{n}}{h} z\right)
$$

이상의 무한 (깊은)지반에 대해 산정된 잔류간극수압의 결 과는 Laplace변환법으로부터 얻어진 Jeng et al. (2006)와 Jeng and Seymour (2007)의 결과와는 전혀 다른 형태의 식 이며, 이에 대해서는 후술한다.

\section{3. 해석결과}

\section{1 검증}

Fig. 2는 Table 1에 나타내는 파랑조건과 지반물성치를 적 용하여 무한시간에서 Cheng et al. (2001)의 수치해와 해석 해 및 본 해석해의 결과를 비교한 것이다. 여기서, Fig. 2(a) 는 $h / L<1 / 20$ 의 조건을 만족하는 얕은 두께의 토층, (b)는 $1 /$ $20<h / L<1 / 2$ 의 조건을 만족하는 유한두께의 토층, (c)는 $h / L>1 / 2$ 의 조건을 만족하는 깊은 두께의 토층에 대한 결과 로 각각은 유한두께의 토층에 대해 전개된 해석해에 각 토층 의 조건을 적용하여 산정한 것이며, 따라서 본 연구에서 제 시하는 얕은 및 무한 (깊은) 토층에 대한 해석해의 식 (33) 과 (48)로부터 추정된 결과가 아니다. 여기서, Cheng et al. (2001)은 유한두께의 토층에 대해서만 해석해와 수치해를 제
시하고 있고, 본 연구와 같은 얕은 및 무한 (깊은) 토층에 대 한 해석해를 제시하고 있지 않다. 그림으로부터 모든 두께의 토층에서 해저지반내 연직깊이가 깊어질수록 잔류간극수압이 증가하고, 해저불투수층에서 잔류간극수압의 기울기가 0 으로 주어지며, 셋 해석결과에서 연직깊이의 변화에 따른 잔류간 극수압의 변화특성이 완전히 일치하므로 본 해석해의 타당성 을 검증할 수 있다.

다음의 Fig. 3은 Table 2에서 제시된 계산조건으로 수행 된 무한시간에서 Jeng et al. (2006)과 본 연구의 해석해에 의한 결과 및 Clukey et al. (1983)에 의한 실험결과를 각각 비교한 것이며, 토층의 두께가 $0.2<h / L<0.3$ 의 범위에 있으 므로 두 해석해에서는 유한두께의 토층에 대한 결과식이 각 각 적용되었다. Jeng et al. (2006)과 본 연구에서 제시한 유 한두께의 토층에 관한 해석해의 결과가 동일하므로 그림으

\begin{tabular}{|c|c|c|c|}
\hline Waves and soil thickness & & Values & \\
\hline Wave period $\bar{T}(s)$ & & 1.76 & \\
\hline Wave height $H(m)$ & & 0.22 & \\
\hline Water depth $d(m)$ & & 0.5 & \\
\hline Soil thickness $h(m)$ & 0.088 & 0.84 & 1.73 \\
\hline Poisson's raio $\mu$ & & 0.49 & \\
\hline Porosity $n^{\prime}$ & & 0.46 & \\
\hline Shear modulus $G\left(k N / \mathrm{m}^{2}\right)$ & & 560 & \\
\hline Permeability $(\mathrm{m} / \mathrm{s})$ & & $4.0 \times 10^{-8}$ & \\
\hline Compressibility of pore-water $\zeta$ & & 0 & \\
\hline Unit weight of soil $\gamma_{\mathrm{s}}\left(\mathrm{N} / \mathrm{m}^{3}\right)$ & & 18,306 & \\
\hline Unit weight of water $\gamma_{\mathrm{w}}\left(\mathrm{N} / \mathrm{m}^{3}\right)$ & & 9,806 & \\
\hline $\begin{array}{c}\text { Coefficient of lateral earth } \\
\text { pressure } k_{0}\end{array}$ & & 0.4 & \\
\hline Consolidation coefficient $c_{v}\left(\mathrm{~m} / \mathrm{s}^{2}\right)$ & & $1.157 \times 10^{-4}$ & \\
\hline$\alpha$ & & 0.246 & \\
\hline$\beta$ & & -0.165 & \\
\hline
\end{tabular}
로부터 두 해석해의 결과가 거의 동일하다는 것을 알 수 있

Table 1 Wave and soil conditions

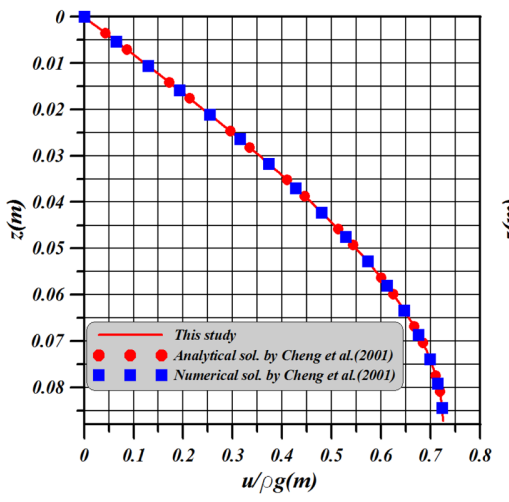

(a) shallow soil thickness

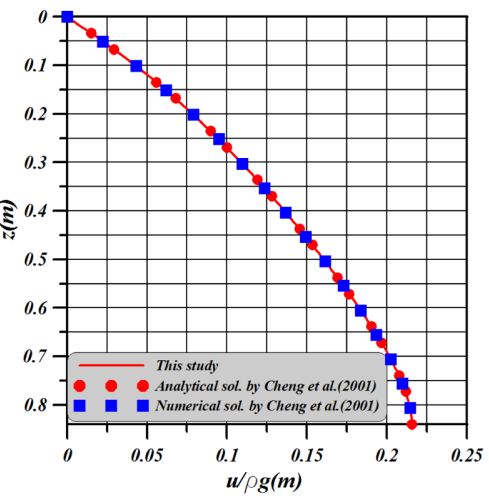

(b) finite soil thickness

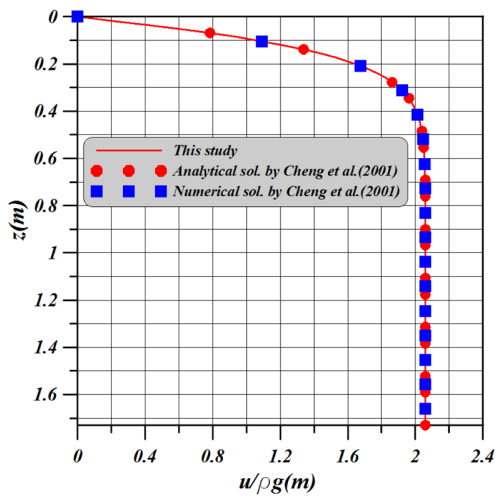

(c) deepsoil thickness

Fig. 2. Comparison of analytical and numerical solutions of residual pore-water pressure. 


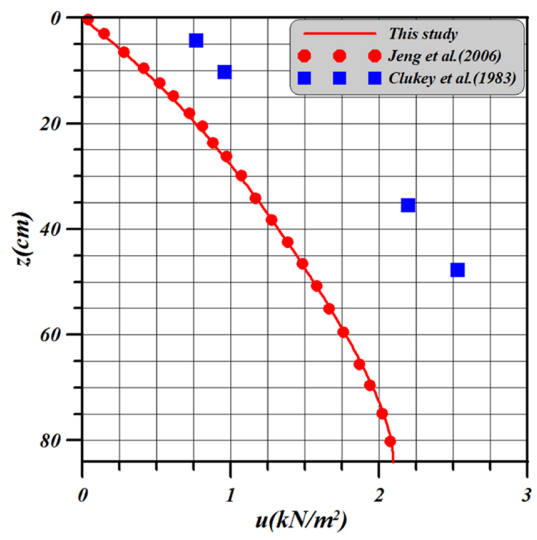

(a)CASE-1

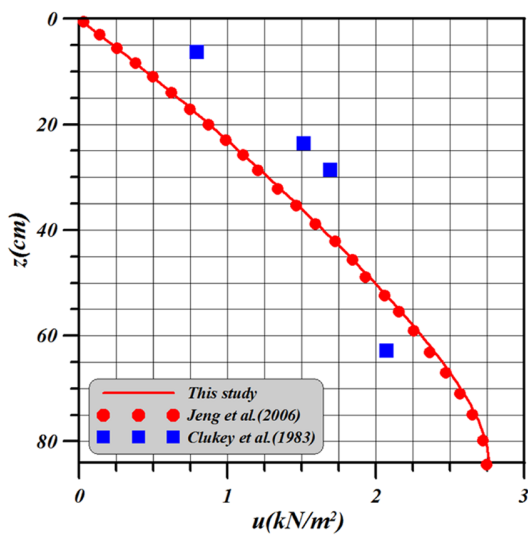

(b)CASE-2

Fig. 3. Comparison of analytical and experimental solutions of residual pore-water pressure.

Table 2. Wave and soil conditions

\begin{tabular}{ccc}
\hline \hline Waves and soil thickness & CASE-1 & CASE-2 \\
\hline Wave period $\bar{T}(s)$ & 1.76 & 2.02 \\
Wave height $H(m)$ & 0.22 & 0.21 \\
Water depth $d(m)$ & 0.5 \\
Soil thickness $h(m)$ & 0.84 \\
Poisson's raio $\mu$ & 0.49 \\
Porosity $n^{\prime}$ & 0.46 \\
Shear modulus $G\left(k N / m^{2}\right)$ & $5.6 \times 10^{5}$ \\
Permeability $(m / s)$ & $4.0 \times 10^{-8}$ \\
Compressibility of pore-water $\zeta$ & 0 \\
Unit weight of soil $\gamma_{\mathrm{s}}\left(\mathrm{N} / \mathrm{m}^{3}\right)$ & 18,306 \\
Unit weight of water $\gamma_{\mathrm{w}}\left(\mathrm{N} / \mathrm{m}^{3}\right)$ & 9,806 \\
Coefficient of lateral earth & 0.4 \\
pressure $k_{0}$ & 0.0001165 \\
$\alpha$ & 0.246 \\
$\beta$ & -0.165 \\
\hline
\end{tabular}

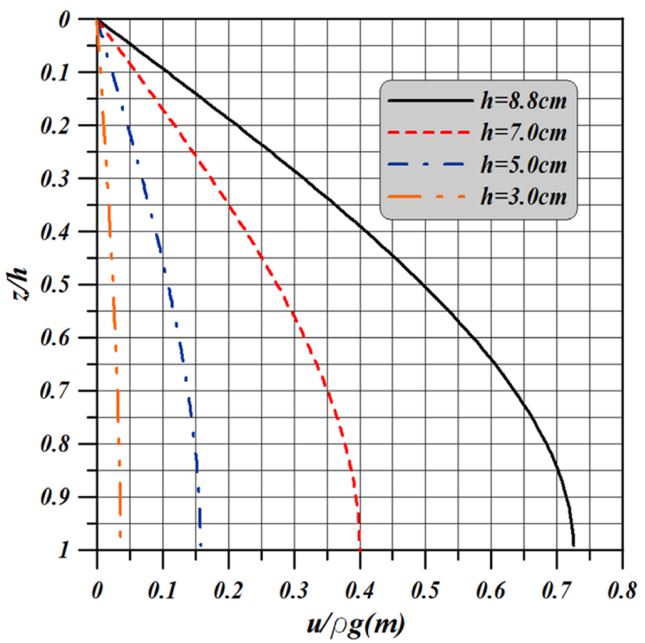

(a) Result of Eq.(28) for finite thickness of seabed
다. 그리고, 실험결과와 비교하면 해저지반내 연직깊이가 깊 어질수록 잔류간극수압이 증가하는 경향은 일치하지만, Fig. 3(a)의 경우는 (b)보다 해석해에 의한 결과와 실험결과에서 차이가 다소 크고, 전체적으로 실험치가 크게 나타나는 것 을 알 수 있다. 이것은 Fig. 3(a)의 파형경사가 더 크며, 따 라서 파의 비선형성에 더 큰 영향을 받은 것으로 추정된다. 또 한, 지반의 비등방성과 소성거동 및 지반내 간극수의 nonDarcy 흐름 등을 고려하면 본 해석해의 유도과정에서 도입 된 이론의 범주내에서는 합리적인 일치성을 나타내는 것으 로 판단된다.

\section{2 얕은 두께}

Table 1의 조건을 사용하여 본 유한두께에 관한 식 (28)과 얕은 두께에 관한 (33)으로부터 산정된 결과를 각각 Fig. 4(a) 와 4(b)에 도시한다. 그림에서 적용된 지반두께는 각각 $h=3 \mathrm{~cm}, 5 \mathrm{~cm}, 7 \mathrm{~cm}$ 및 $8.8 \mathrm{~cm}$ 의 경우로 모두 $h / L<1 / 20$ 인 얕은 두께의 해저지반 조건에 상당한다. 일반적으로 유한두 께에 관한 식 (28)에서 지반두께를 극한적으로 작게 하면 얕

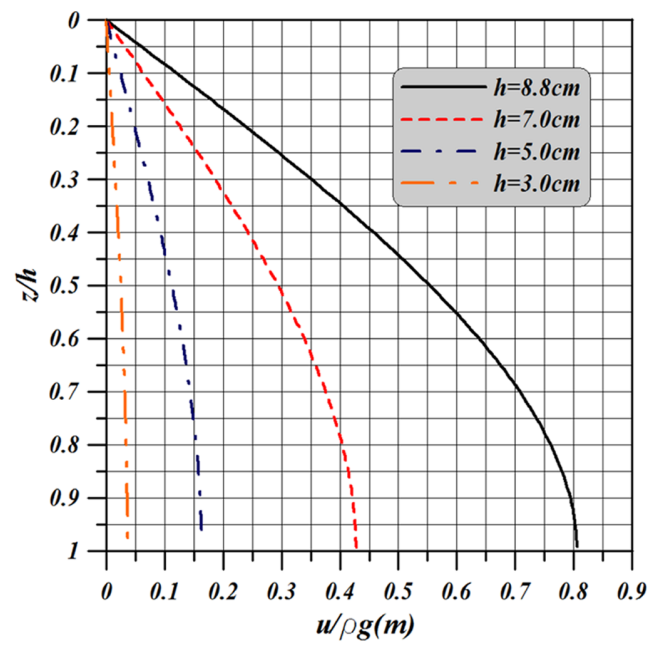

(b)Result ofEq.(33)for shallow thickness of seabed

Fig. 4. Residual pore-water pressure head. 
은 두께에 관한 식 (33)의 결과로 수렴될 것으로 추정될 수 있으며, 이러한 사실을 Fig. 4로부터 확인할 수 있다. 즉, 그 림에서 $h=8.8 \mathrm{~cm} \rightarrow 7 \mathrm{~cm} \rightarrow 5 \mathrm{~cm} \rightarrow 3 \mathrm{~cm}$ 로 지반두께가 점 점 작아질수록 두 결과에서 차이가 점점 줄어들고, $h=3 \mathrm{~cm}$ 와 $5 \mathrm{~cm}$ 의 경우는 두 결과가 거의 일치한다. 따라서, 유한두 께에 관한 식 (28)에서 잔류간극수압의 응답은 지반두께를 작 게 하면 점근적으로 극한상태의 (33)에서 잔류간극수압의 응 답에 접근된다는 것을 확인할 수 있다. 그리고, Fig. 4(a)와 (b)의 두 결과로부터 해저지반내 연직깊이가 깊을수록, 또한 지반두께가 두꺼울수록 잔류간극수압에 의한 압력수두가 증 가한다는 사실을 알 수 있다.

\section{3 무한 (깊은)두께}

다음에 나타내는 Fig. 5는 유한두께의 해저지반에 관한 식 (28)에 Table 1의 파랑 및 지반조건을 적용하여 잔류간극수 압에 의한 압력수두를 도시한 결과이다. 그림에서는 $h / L>1 /$

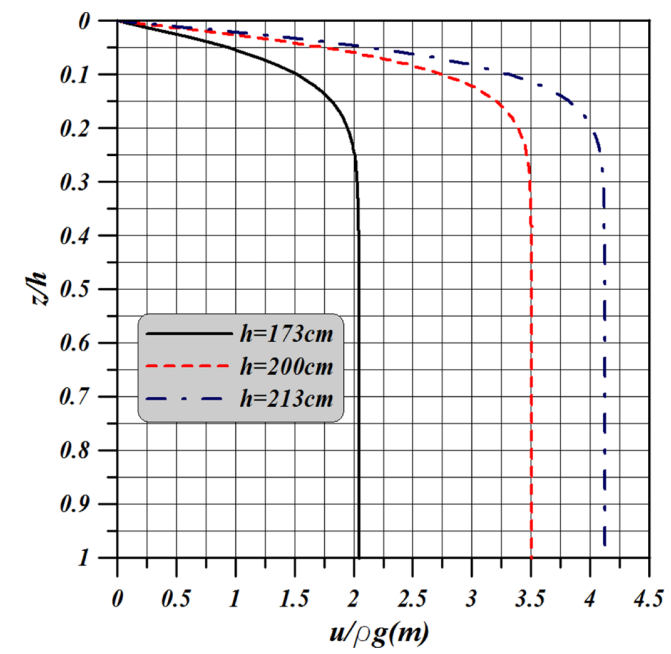

Fig. 5. Residual pore-water pressure head by Eq. (28) for finite soil thickness of this study.

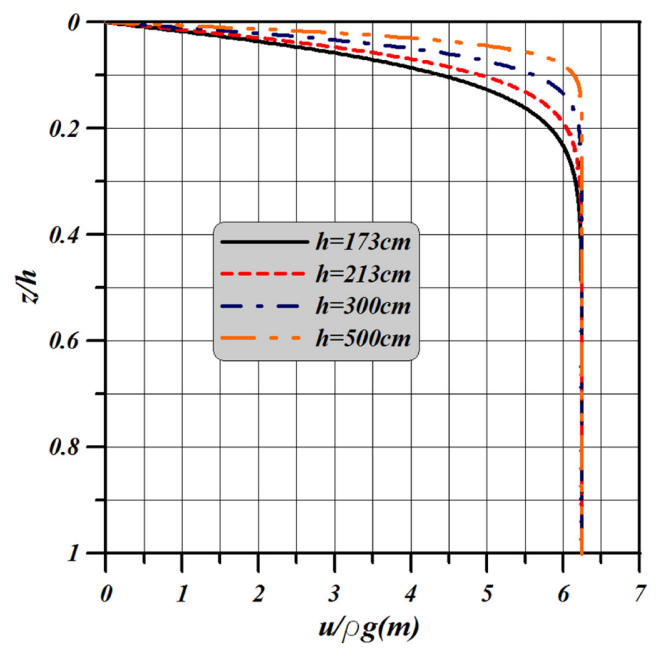

(a) Non-dimensional vertical depth
2 인 조건을 만족하는 여러 종류의 지반두께를 적용하여 지반 두께의 변화에 따른 해석해의 거동을 나타낸다. 여기서, 지반 두께가 두꺼워질수록 잔류간극수압에 의한 압력수두가 증가 하고, 어떤 연직깊이 이하에서는 균등한 값을 나타내며, 균등 한 압력수두가 나타나는 연직깊이는 지반두께가 두꺼워질수 록 깊어진다는 것을 알 수 있다.

한편, 식 (28)에서 Table 1의 조건하 $h / L>213 \mathrm{~cm}$ 의 경우 는 해석해가 발산하여 결과가 산정될 수 없으며, 이의 경우 는 무한 (깊은)두께의 해저지반에 관한 식 (48)로부터 추정되 어야 한다. Table 1의 조건하에 이를 나타낸 것이 Fig. 6의 결과이다. Fig. 6(a)로부터 $h=173 \mathrm{~cm}, 213 \mathrm{~cm}$ 의 결과가 식 (28)에 의한 Fig. 5의 결과와는 달리 보다 큰 값을 가진다는 것을 알 수 있다. 이로부터 유한두께에 관한 식 (28)로부터 무한두께인 (48)으로의 점근적인 접속이 불가능하며, 두 식에 의한 결과 사이에 두 식으로부터 얻어질 수 없는 불연속의 어 떤 영역이 존재한다는 것을 알 수 있다. 따라서, 무한 (깊은) 두께의 해저지반에 관해서는 식 (34)와는 다른 보다 합당한 전단응력으로부터 새로운 추정식이 산정될 필요가 있는 것으 로 판단된다. 다음으로, 연직깊이를 차원량으로 나타낸 Fig. 6(b)로부터 지반두께와의 관계없이 동일한 잔류간극수압의 수 두가 얻어진다는 것을 확인할 수 있고, 무차원량으로 나타낸 Fig. 6(a)에서 차이를 나타내는 것은 무차원화로 적용되는 지 반두께 $h$ 의 값이 다르기 때문이다.

한편, Jeng and Seymour (2007)은 무한두께의 해저지반에서 경계조건식 (12) 대신에 다음과 같은 경계조건을 부과하고 있다.

$$
u(\infty, t)=0
$$

따라서, 무한지반에 대해 식 (11), (13) 및 (49)을 만족하는 (8)의 해로 Laplace변환법을 적용하여 다음의 해석해를 제시 하고 있다.

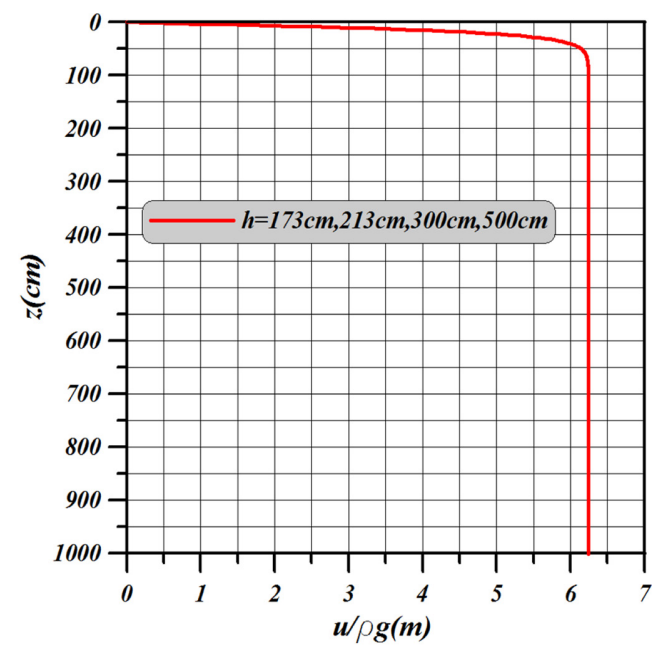

(b) Dimensional vertical depth

Fig. 6. Residual pore-water pressure head obtained by Eq. (48) for deep soil thickness of this study. 


$$
u(z, t)=\frac{2 A}{c_{v} \lambda^{3}}\left[1-\left(\frac{\lambda z}{2}+1\right) e^{-\lambda z}-\frac{1}{\pi} \rho_{0}^{0} \frac{e^{-r c_{v} \lambda^{2} t}}{r(r+1)^{2}} \sin (\sqrt{r} \lambda z) d r\right]
$$

여기서, $\lambda=-k / \beta$ 이고, $A$ 는 다음의 식으로 정의된다.

$$
A=\frac{\rho_{\text {sub }} g\left(1+2 k_{0}\right)}{3 \bar{T}}\left[\frac{3 p_{0} k}{\alpha \rho_{s u b} g\left(1+2 k_{0}\right)}\right]^{-1 / \beta}
$$

식 (50)에서 $t \rightarrow \infty$ 의 경우 우변의 반무한적분항은 0 으로 수렴되기 때문에 정상상태의 잔류간극수압은 다음의 식으로 표현될 수 있다.

$$
u(z)=\frac{2 A}{c_{v} \lambda^{3}}\left[1-\left(\frac{\lambda z}{2}+1\right) e^{-\lambda z}\right]
$$

식 (52)에서 $z \rightarrow \infty$ 에서 이므로 $e^{-\lambda z} \rightarrow 0$ 극한치는 다음의 식으로 나타난다.

$$
u(\infty)=\frac{2 A}{c_{v} \lambda^{3}}
$$

여기서, 식 (53)은 Jeng and Seymour (2007)의 경계조건식 (49)를 만족하지 않는 모순점이 나타난다. 한편, 무한 (깊은)두 께의 해저지반에 대해 동일한 잔류간극수압의 해석해를 나타 내는 Jeng et al. (2006)에서는 식 (49) 대신에 다음의 경계 조건을 부과하고 있다.

$$
\frac{\partial u(h, t)}{\partial z}=0 \text { or } u(\infty, t)=0
$$

식 (50)은 (54)의 첫 번째 경계조건을 만족하므로 Jeng and Seymour (2007)에 의한 경계조건식 (49)는 오류로 판단된다.

다음의 Fig. 7에 나타내는 결과는 식 (52)에 나타낸 Jeng and Seymour (2007)의 해석해로부터 진행파의 주기를 파라 미터로 산정된 잔류간극수압의 압력수두를 나타내고 있다. 그 림으로부터 진행파의 주기 $\bar{T}=1.76 \mathrm{~s}$ 에서 가장 큰 값을 나 타내고, 그 이후 주기가 증가하면 역으로 값의 크기가 감소 한다. 따라서, 진행파의 주기와 잔류간극수압은 선형관계로 주 어지지 않고, 잔류간극수압이 최대로 되는 어떤 주기가 존재 한다는 것을 알 수 있다. 다음으로, 진행파 주기 $\bar{T}=1.76 \mathrm{~s}$ 로 고정된 본 해석해에 의한 Fig. 6의 결과와 Jeng and Seymour (2007)의 식(52)에 의한 Fig. 7의 결과 중에 진행파 주기 $\bar{T}=1.76 \mathrm{~s}$ 의 결과를 비교하면 두 결과는 완전히 동일하 다는 것을 확인할 수 있다. 따라서, 무한두께의 해저지반에 대 해 새롭게 산정된 본 연구의 해석해 식 (47) 및 (48)은 Jeng and Seymour (2007)에 의한 해석해 식 (50) 및 (52)와 동일 한 잔류간극수압을 나타낸다. 이로부터 본 연구의 결과는 Jeng et al. (2006)에 의해 지적된 McDougal et al. (1989)에서의 오류를 수정하여 재산정된 해석해인 것으로 판정된다. 여기 서, 본 해석해의 식 (47)과 (48)에 포함된 지반두께 $h$ 는 계산 과정에서 소거되어 연직깊이에 따른 잔류간극수압의 값에는 영향을 미치지 않는다는 것을 Fig. 6(b)로부터 알 수 있다.

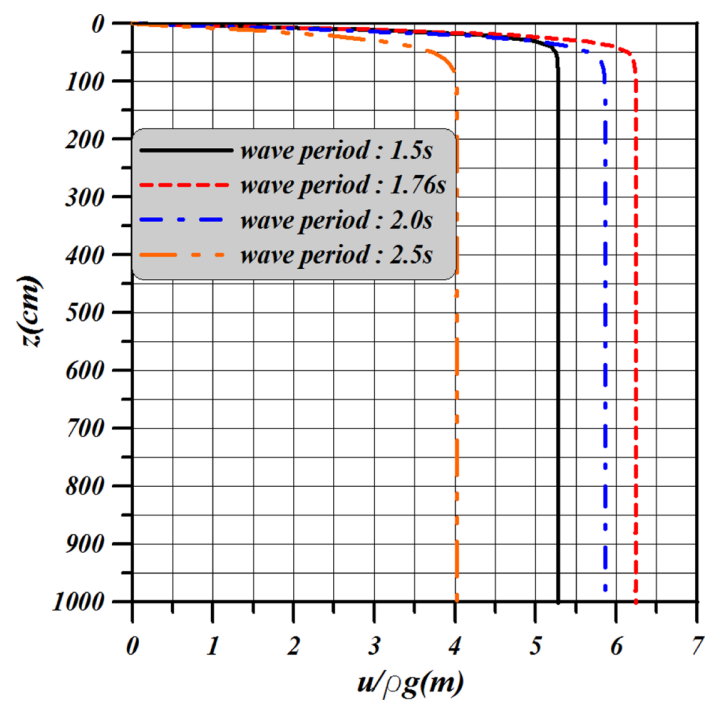

Fig. 7. Residual pore-water pressure head obtained from Eq. (52) presented by Jeng and Seymour (2007) for deep soil thickness.

\section{4. 맺음말}

본 연구에서는 Fourier급수전개법과 변수분리법을 적용하여 Jeng et al. (2006)에 의해 지적된 McDougal et al. (1989)에서 의 오류를 수정한 얕은, 유한 및 무한 (깊은)두께의 해저지반 에서 잔류간극수압을 나타내는 해석해를 재산정하였다. 특히, 무한 (깊은)두께의 경우는 Laplace변환법에 의한 Jeng and Seymour (2007)의 해석해와의 비교·검토 및 유한두께의 경우 는 기존의 해석해, 수치해석 및 실험결과와의 비교·검토로부 터 본 해석해의 정당성을 확인할 수 있었다. 여기서, 무한 (깊 은)두께의 본 해석해는 Jeng and Seymour (2007)의 해석해보 다는 수치적분 등이 수행될 필요가 없는 보다 간단한 식으로 판단된다. 또한, 본 연구 및 기존의 연구에서 유한두께의 해석 해에 지반두께의 극한적으로 작게 한 경우 얕은 두께로 점근 적인 접근은 가능하지만, 지반두께의 극한적으로 크게 한 경우 무한두께로의 접근은 불가능하며, 따라서 유한두께와 무한두께 의 사이에는 불연속적인 영역이 존재한다는 것을 알 수 있었 다. 이에 대한 하나의 대책으로 식 (34)에 나타낸 전단응력에 $e^{-k z}$ 와 $e^{-k \delta z}$ 의 항을 부가한 새로운 전단응력의 추정식으로부 터 잔류간극수압을 재추정할 필요가 있을 것으로 판단된다.

\section{감사의 글}

이 연구는 해양수산부/한국해양과학기술진흥원의 연구과제 (PJT200538)로 수행된 연구임.

\section{References}

Biot, M. A.(1941). General theory of three-dimensional consolidation, J. Applied Physics, 12, 155-164. 
Castro, G. (1975). Liquefaction and cyclic mobility of saturated sands, J. Geotechnical Engineering Division, 101(GT6), 551569.

Cheng, L., Sumer, B. M. and Fredsoe, J.(2001). Solution of pore pressure build up due to progressive waves, Int. J. Numerical and Analytical Methods in Geomechanics, 25, 885-907.

Clukey, E. C., Kulhawy, F. H. and Liu, P. L.-F.(1983). Laboratory and field investigation of wave-sediment interaction, Joseph $\mathrm{H}$. Defrees Hydraulic Laboratory, School of Civil and Environmental Engineering, Cornell University, Ithaca, NY.

Clukey, E. C., Kulhawy, F. H., Liu, P. L.-F. and Tate, G. B.(1985). The impact of wave loads and pore-water pressure generation on initiation of sediment transport, Geo-Marine Letters, 5, 177183.

de Alba, P., Seed, H. B. and Chan, C. K.(1976). Sand liquefaction in large-scale simple shear tests, J. Geotechnical Engineering Division, 102, 909-928.

Hamada, M., O'Rourke, T. D. and Yoshida, N.(1994). Liquefaction-induced large ground displacement, 13th ICSMFE, Performance of Ground Soil during Earthquake, 93-108.

Ishihara, K.(1993). Liquefaction and flow failure during earthquakes, Geotechnique, 43(3), 351-415.

Ishihara, K., Acacio, A. and Towhata, I.(1993). Liquefaction induced ground damage in Dagupan in the July 16, 1990 Luzon earthquake, Soils and Foundations, JSSMFE, 33(1), 133-154.

Jeng, D. S.(1997). Wave-induced seabed response in front of a breakwater, $\mathrm{PhD}$ Thesis, The University of Western Australia.

Jeng, D.S.(2008). Effects of wave non-linearity on residual pore pressure in marine sediments, The Open Civil Eng. J., 2, 63-74.

Jeng, D. S. and Seymour, B. R.(2007). Simplified analytical approximation for pore-water pressure buildup in marine sediments, J. Waterway, Port, Coastal, and Ocean Eng., ASCE, 133(4), 309-312.

Jeng, D. S., Seymour, B. R. and Li J.(2006). A new approximation for pore pressure accumulation in marine sediment due to water waves, Research Report No. R868, School of Civil Engineering, University of Sydney, Sydney, Australia.

Kirca, V. S. O., Sumer, B. M. and Fredsoe, J.(2013). Residual liquefaction of seabed under standing waves, J. Waterway, Port, Coastal, and Ocean Eng., ASCE, 139, 489-501.

Lee, K. H., Kim, D. S., Kim, K. H., Kim, D. W. and Shin, B. S.(2014). Analysis method of partial standing wave-induced seabed responses in finite soil thickness under arbitrary reflection, J. Korean Society of Coastal and Ocean Engineers, 26(5),
300-313.

McDougal, W. G., Tsai, Y. T., Liu, P. L.-F. and Clukey, E. C.(1989). Wave-induced pore water pressure accumulation in marine soils, J. Offshore Mechanics and Arctic Eng., 111, 1-11.

Sassa, S. and Sekiguchi, H.(1999). Wave-induced liquefaction of beds of sand in a centrifuge, Geotechnique, 49(5), 621-638.

Sassa, S. and Sekiguchi, H.(2001). Analysis of wave-induced liquefaction of sand beds, Geotechnique, 51(2), 115-126.

Sassa, S., Sekiguchi, H. and Miyamoto, J.(2001). Analysis of progressive liquefaction as a moving boundary problem, Geotechnique, 51(10), 847-857.

Sawicki, A. and Mierczynski, J.(2005). Wave-induced stresses and liquefaction in seabed according to the Biot-type approach, Archives of Hydro-Eng. And Environmental Mechanics, 52(2), 131-145.

Seed, H. B. and Idriss, I. M.(1971). Simplified procedure for evaluating soil liquefaction potential, J. Soil Mechanics and Foundations Division, ASCE, 97(SM9), 1249-1273.

Seed, H.B. and Idriss, I. M.(1982). Ground motion and soil liquefaction during earthquakes, EERI Monograph, Earthquake Engineering Research Institute.

Seed, H. B., Lee, K. L.(1966). Liquefaction of saturated sands during cyclic loading, J. Soil Mechanics and Foundations Division, ASCE, 92, 105-134.

Seed, H. B., Pyke, R. M. and Martin, G. R.(1978). Effects of multidirectional shaking on pore pressure development in sands, J. Geotechnical Division, ASCE, 104, 27-44.

Seed, H. B., Rahman, M. S.(1978). Wave-induced pore pressure in relation to ocean floor stability of cohesionless soils, Marine Geotechnology, 3(2), 123-150.

Sumer, B. M. and Cheng, N. S.(1999). A random-walk model for pore pressure accumulation in marine soils, 9th Intl. Offshore and Polar Eng. Conference, ISOPE, 521-528.

Yamamoto, T., Koning, H. L., Sellmeijer, H. and Hijum, E.V.(1978). On the response of a poro-elastic bed to water waves, J. Fluid Mech., 87, 193-206.

Zen, K. and Yamazaki, H.(1991). Field observation and analysis of wave-induced liquefaction in seabed, Soil and Foundation, 31(4), 161-179.

Received 1 April, 2015

Accepted 8 May, 2015 